14th July a French steamer, the Primoquet, arrived from Toulon; and as several of her crew were affected with cholera, she was sent in shore of the English squadron to be cleaned out, and to undergo a sort of quarantine. The weather at that time was tempestuous, and the wind blew towards the Diamond from the position of the steamer and her tents.

Dr. Mackay next proceeds to give an account of distinct outbreaks of cholera on board the Agamemnon, at Varna and at Old Fort, during August and September, 1854; of a case from camp at Balaclava, in November; of seven cases caused by communication with H.M.S. Industry, and to our minds aatisfactorily proved, in December of the same year; of a case from the Medina, in May, 1855; and of two other cases from the camp at Yenikale Straits of Kertch.

The whole of these cases are recorded in a spirit of faithfulness, impartiality, and with extreme care; and while some of them must be regarded as affording only strong presumptive evidence of the agency of contagion in the diffusion of this disease, there are others which, to our minds, bear unequivocal evidence in favour of that view of the question.

The pamphlet forms a valuable addition to our knowledge of the etiology of the cholera epidemic that proved so disastrous to our soldiers and sailors of the Crinean expedition.

Statistics of the University Lying-in Hospital, Montreal. By GeorGe E. Fenwick, M.D., Registrar. Montreal, 1857. Pamphlet.

The Lying-in Hospital which furnished these statistics was established in connexion with the University, througl the exertions of the late Dr. M'Culloch, who was Professor of Midwifery in $M^{6}$ Gill College, aided by the zealous efforts of benevolent ladies. Since its first opening, 1753 females have boen confined. As the system of enregistration was not very perfect at the commencement of its career, the total number cannot be relied on with accuracy. We, however, find that 46 children were still-born, and of these 30 were saved by artificial respiration and other means; and latterly the Marshall Hall Method has been employed with great success. Triplets occurred once: the first child came breech foremost, and was lost; the other two followed soon after. In both instances the presentations were the first position of the vortex. The placenta covered an immense extent of uterine surfice. It appeared as if originally it had consisted of three distinct placentæ. The funis was short in each, so much so that in the first birth the cord was much stretched and pressed upon, which accounts for the fatal result. In regard to menstruation during labour, there is a case mentioned of one woman who menstruated regularly to within 60 days of her confinement: the child was born at the full time. Amongst the complications were four cases of puerperal convulsions, all fatal to the mothers, three of the children being saved; and one monstrosity, anencephaloid, with a single nostril. The facts embodied in these statistics are useful and interesting, and Dr. Fenwick has performed his task with great ability.

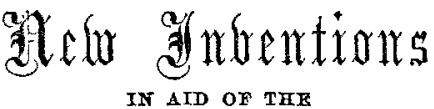

\section{PRACTICE OF MEDICINE AND SURGERY.}

\section{EYE-DROP CANULA, AND DWARF LANCET.} BY WALTER JESSOP, ESQ., M.R. C.S., CHELTENHAM.

I Have found the "drop canula" so useful for the purposes of applying various solutions to the eye, that $I$ now venture to draw the attention of the profession engaged in ophthalmic practice to its advantages over the camel's-hair pencil, cut quills, \&c. The drop canula can be readily carried in the waistcoat-pocket; the quill portion should be made of platina, the case or holder in which it slides either of ivory or ebony- the latter is preferable, as no part of the little instrument will become stained. On more than one occasion I have seen much suffering induced by a loose hair from the camel pencil, and a quill becomes stained, readily wears out, and is pretty generally borrowed by one's patients. I should observe that it is desirable to wipe the canula after each time of using, as I have known instances where a drop of a solution of nitrate of silver occasioned dilatation of the pupil, through the manipulator having just previously used a solution of atropine. This, however, might equally happen to a quill, and was no fault of the canula, which I am sure will be found very useful, and may be purchased for a few shillings from any instrument-maker who may choose to make it.

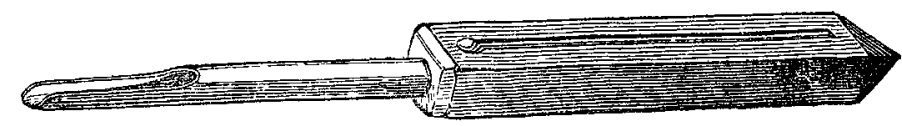

\section{Eye-drop canula.}

I enclose a sketch (real size) of a lancet, which I find suitable for all ordinary purposes. Its small size disarms anxiety in the patient, and with children, or the highly nervous, admits of being readily hidden between the fingers and thumb, affording the surgeon an opportunity of relieving the sufferer without exciting needless alarm.

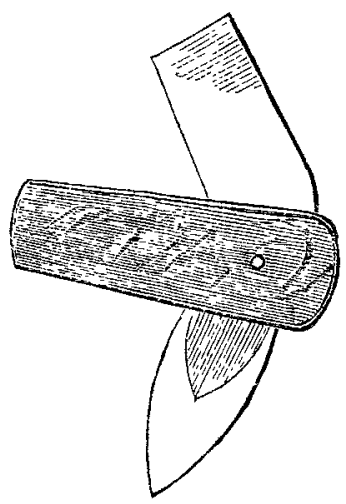

Dwarf lancet

Very few cases of simple abscess require a more formidable instrument for their relief.

Cheltenham, Nov. 1857.

HEAITH OF LONDON DURING THE WEEk ENDING SATURDAX, November 28rH.-The sickness which is now so generally diffused throughout the metropolitan population continues to develop itself in a high rate of mortality. The deaths registered in London, which rose in the previous week to 1382 , were of nearly equal amount in the week that ended last Saturday, (November 2Sth,) the number having been 1373 . In the ten years, $134 i-56$, the average number of deaths in the weeks corresponding with last week was 1183 . But the deaths of last week occurred in an increased population, and with the view of comparison the average must be raised in proportion to the increase, in which case it will become 1301. It appears, therefore, that the deaths now returned exceed by 72 the number which the average rate of mortality, as ascertained for the close of November, would have produced. At this period in 1847 influenza began to be very prevalent, and in a population which was not so great as it is now, the deaths from all causes rose to 1677 . The births registered last week exceeded the deaths in the same period by 227 . In this return the number of cases in which influenza is recorded under its specific designation is only 13 ; in the previons week it was 9. The epidemic has certain distinguishing features; and in all cases where medical attendants observe it, either as the primary disease, or as supervening on pulmonary or other complaints, it is important that it should be specially mentioned by that name which is both popular and scientific. It deserves to be noticed that the deaths referred to diseases of the respiratory organs, which class does not include phthisis, were precisely the same numerically as those in the same class in the previous week, the number in each case having been 390 . This number exceeds the corrected average of ten weeks corresponding with last week by 102 . Of the 390 , by far the largest proportion arose from bronchitis-namely, 217 deaths. Of 43 cases in which scarlatina was fatal, 4 occurred in the sub-district of St. John, Westminster, and also 4 in that of Lambeth Church (2nd part.) 